\title{
THE EFFECT OF OBTURATION TECHNIQUE ON THE FRACTURE RESISTANCE OF ENDODONTICALLY TREATED TEETH OBTURATED WITH BIOCERAMIC SEALER (IN VITRO STUDY)
}

\author{
Medhat Taha Elfaramawy* and Tariq Yehia**
}

\begin{abstract}
Aim of the study: This study evaluated the effect of obturation technique on the fracture resistance of endodontically treated teeth obturated with bioceramic sealers compared to resinbased sealers.

Methods: Ninety-one ( $n=91)$ freshly human extracted single rooted teeth were selected. The samples were biomechanically prepared and classified according to the obturation technique and type of the sealer used into five groups as follows: Group $1(n=21)$ obturated with cold lateral compaction technique using gutta-percha and AD-seal sealer (Meta Biomed, Korea). Group 2 (n=21) obturated with warm vertical compaction technique using gutta-percha and $\mathrm{AD}$-seal sealer. Group $3(n=21)$ obturated with cold lateral compaction technique using gutta-percha and MTA filapex sealer (Angelus, Brazil). Group 4 ( $n=21$ ) obturated with warm vertical compaction technique using gutta-percha and MTA filapex sealer. Group $5(\mathrm{n}=7)$ Control group (unobturated). The samples were further classified according to the observation time into: subgroup A ( $n=7)$ evaluated after one week, subgroup B $(n=7)$ evaluated after two weeks and subgroup C $(n=7)$ evaluated after one month. Samples were loaded vertically after obturation using Universal Testing Machine until fracture.
\end{abstract}

Results: MTA filapex group showed higher fracture resistance values than the other groups with no significant difference. No significant difference was found between the subgroups evaluated at different time intervals.

Conclusion: The technique of root canal obturation didn't significantly affect tooth fracture resistance at different time intervals.

KEYWORDS: fracture resistance, obturation technique, bioceramics.

* Associate Professor, Endodontic Department, Faculty of dentistry, Ainshams University.

** Lecturer, Endodontic Department, Faculty of Dentistry, Ain Shams University, Cairo, Egypt 


\section{INTRODUCTION}

Cold lateral condensation (CLC) is widely applied obturation technique with advantages of controlled placement of gutta-percha (GP) in the root canal ${ }^{(1)}$. Unfortunately, clinicians complained of high risk of root cracking and fracture with forceful use of spreaders in CLC. Warm vertical condensation (WVC) of GP allows the placement of a homogeneous filling into the root canal system ${ }^{(2)}$. This technique is more effective in filling lateral and accessory canals than CLC ${ }^{(3)}$. However, the main disadvantage of WVC is difficult length control. Rapid insertion can cause overextension, whereas slow insertion may result in underfilling ${ }^{(1)}$.

Vertical root fracture is more common in endodontically treated teeth than vital teeth. This can be due to extensive caries, access cavity design and root canal preparation ${ }^{(4,5)}$. Bioceramics are thought to reinforce root structure. However, the effect of sealers on fracture resistance after endodontic treatment is questionable. Uzunoglu-Özyürek ${ }^{(6)}$ concluded that root canal sealers can increase fracture resistance of endodontically treated teeth. On the other hand, Kim et al ${ }^{(7)}$ concluded that methacrylate resin-based sealers were not able to strengthen dentin after endodontic treatment.

The purpose of this study was to compare fracture resistance of roots after obturation with Ad-seal and MTA-Fillapex sealers, using CLC and WVC techniques.

\section{MATERIALS AND METHODS}

Ninety-one extracted human single rooted teeth with no signs of internal or external resorption were used. Teeth were decoronated using diamond disc mounted in a low-speed hand piece under water coolant to standardize roots length at $13 \mathrm{~mm}$. Size 15 $K$ file was used to assure patency of the canal and the apical foramen. The working length was established by subtracting $1 \mathrm{~mm}$ from the length obtained when the file tip just appeared at the apical foramen. Root canals were instrumented using ProTaper Universal rotary files (Dentsply, Maillefer, Switzerland) up to F4. Irrigation was made with $2.5 \% \mathrm{NaOCl}$ (Clorox, Egypt) during the instrumentation. At the end of the preparation, each canal received final flush with $5 \mathrm{ml}$ of $2.5 \% \mathrm{NaOCl}$ irrigation, $5 \mathrm{ml}$ of $17 \%$ EDTA (Meta Biomed, Korea), and $3 \mathrm{ml}$ of saline (Novartis, Egypt), to the remove smear layer.

The samples were classified according to the obturation technique and type of the sealer used into five groups as follows; Group $1(n=21)$ obturated with cold lateral compaction technique using guttapercha and AD-seal sealer (Meta Biomed, Korea). Group $2(n=21)$ obturated with warm vertical compaction technique using gutta-percha and $\mathrm{AD}$ seal sealer. Group $3(n=21)$ obturated with cold lateral compaction technique using gutta-percha and MTA filapex sealer (Angelus, Brazil). Group $4(n=21)$ obturated with warm vertical compaction technique using gutta-percha and MTA filapex sealer. Group 5 ( $n=7$ ) Control group (unobturated). WVC was made using E \& Q obturation system (Meta Biomed, Korea) according to the manufacturer's instructions. Quality of obturation was confirmed radiographically, where specimens containing voids have been excluded. All roots were kept in $100 \%$ humidity at $37^{\circ} \mathrm{C}$ for 24 hours to ensure complete setting of sealers. Roots were covered with siliconbased impression material up to $4 \mathrm{~mm}$ apical to the coronal margin to simulate periodontal ligaments. The samples were further classified according to the observation time into: subgroup $A(n=7)$ evaluated after one week, subgroup $B(n=7)$ evaluated after two weeks, and subgroup $C(n=7)$ evaluated after one month. Then each root was mounted as follows:

A plastic syringes $\left(10 \mathrm{~cm}^{3}\right)$ were used to form the sample block which consisted of a tooth imbedded perpendicularly in self-cure acrylic resin. The acrylic blocks including the samples were mounted 
on the lower fixed compartment of Instron testing machine (Model 3345, England) with a load cell of $5 \mathrm{KN}$ and then secured by tightening screws. A cylindrical steel rod with round tip $2 \mathrm{~mm}$ in diameter attached to the upper part of the universal testing machine was used to apply force on the root at a crosshead speed of $1 \mathrm{~mm} / \mathrm{min}$ until fracture occurred. The load of failure was defined by an audible crack and confirmed by sharp drop at load deflection curve recorded using computer software in Newtons $(>25 \%)$.

Numerical data were presented as mean, standard deviation (SD) values. Data were explored for normality by checking the data distribution, calculating the mean and median values and using Kolmogorov-Smirnov and Shapiro-Wilk tests and showed parametric distribution. Homogeneity of variance was tested using Levene's test. One-way ANOVA followed by Tukey's post hoc test was used for intergroup comparisons. The significance level was set at $p \leq 0.05$ within all tests. Statistical analysis was performed with $\mathrm{R}$ statistical analysis software version 4.0.4 for windows ( $\mathrm{R}$ Core Team (2021). R: A language and environment for statistical computing. R Foundation for Statistical Computing, Vienna, Austria. URL https://www.Rproject.org).

\section{RESULTS}

Mean and Standard deviation (SD) values for intergroup comparison of fracture resistance values were presented in table (1) and figure (1).

Within Ad-seal groups, WVC technique showed higher values for fracture resistance than CLC technique. Meanwhile, both techniques showed close values within the MTA filapex groups. No statistically significant difference was found between CLC and WVC techniques neither at Ad-seal groups nor MTA filapex groups. WVC+MTA filapex subgroup $C$ showed the highest mean value $(689 \pm 65)$, while CLC+Ad-seal subgroup A showed the least mean value $(640 \pm 57)$. Statistically, there was no significant difference between the four groups at different observation periods $(\mathrm{p}<0.05)$.

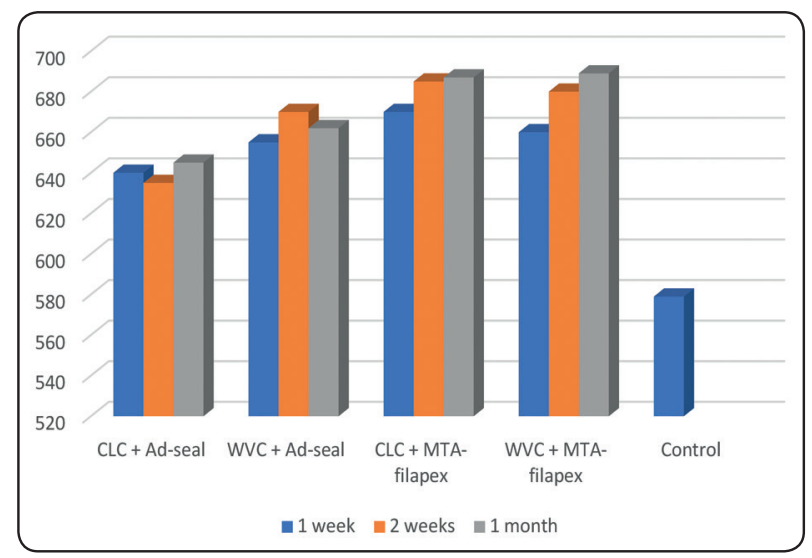

Fig. (1): Column chart showing mean fracture resistance $(N)$ in different subgroups.

TABLE (1): Descriptive statistics and comparison of fracture resistance between groups (ANOVA).

\begin{tabular}{|c|c|c|c|c|c|}
\hline Group & $\begin{array}{c}\text { Group 1 } \\
\text { Subgroup }\end{array}$ & $\begin{array}{c}\text { Group 2 } \\
\text { (CLC + AD-seal) }\end{array}$ & $\begin{array}{c}\text { Group 3 } \\
\text { (WVC + AD-seal) }\end{array}$ & $\begin{array}{c}\text { Group 4 }+ \text { MTA filapex) } \\
\text { (WVC+MTA filapex) }\end{array}$ & $\begin{array}{c}\text { Group 5 } \\
\text { control }\end{array}$ \\
\hline Subgroup A (1 week) & $640 \pm 57^{\mathrm{a}}$ & $655 \pm 50^{\mathrm{a}}$ & $670 \pm 75^{\mathrm{a}}$ & $660 \pm 61^{\mathrm{a}}$ & \\
\cline { 1 - 5 } Subgroup B (2 weeks) & $635 \pm 80^{\mathrm{a}}$ & $670 \pm 63^{\mathrm{a}}$ & $685 \pm 80^{\mathrm{a}}$ & $680 \pm 68^{\mathrm{a}}$ & $579 \pm 69^{\mathrm{a}}$ \\
\cline { 1 - 5 } Subgroup C (1 month) & $645 \pm 73^{\mathrm{a}}$ & $662 \pm 54^{\mathrm{a}}$ & $687 \pm 61^{\mathrm{a}}$ & $689 \pm 65^{\mathrm{a}}$ & \\
\hline
\end{tabular}

Significance level $p<0.05$ (Kruskall Wallis: $P=.237$ )

Mean values with the same letter are insignificantly different 


\section{DISCUSSION}

Vertical root fracture (VRF) is a serious complication that can occur in up to $20 \%$ endodontically treated teeth and ends with tooth extraction ${ }^{(6)}$. Instron testing machine was used for measurement of fracture resistance of specimens. Vertical force was applied at $90^{\circ}$ angle to the roots face until VRF occurred ${ }^{(8)}$. This technique was found to be more clinically relevant as it simulates the normal periodontal attachment, with more homogenous stresses distribution ${ }^{(9,10)}$.

No statistically significant difference was found between CLC and WVC techniques, neither at Adseal groups nor MTA filapex groups. This is consistent with previous studies, in which the obturation quality, long-term outcome, and postoperative pain prevalence were similar between the CLC and WVC groups ${ }^{(11)}$. On the other hand, our results disagree with Lertchirakarn et al., who stated that there is more risk of VRF with CLC technique ${ }^{(12)}$.

MTA filapex sealer had the higher mean value for fracture resistance than Ad-seal sealer, without statistically significant difference. The results of this study disagree with many studies in which the resinbased sealer showed the highest fracture resistance values than other sealers ${ }^{(13,14,15)}$. This may be attributed to the formation of a covalent bond between the open epoxide ring of the epoxy resin sealer and amino groups in the exposed collagen network of radicular dentin ${ }^{(16)}$. On the other hand, our results are in agreement with Nagpal et al ${ }^{(17)}$ and Patil et al ${ }^{(18)}$, in which roots obturated with bioceramic sealers showed higher fracture resistance than roots obturated with other sealers. This can be related to the structural modification of radicular dentin by incorporation of sealer $\mathrm{Ca}$ and $\mathrm{Si}$, resulting in higher strength ${ }^{(19)}$. Such structural modification becomes more prominent with time, which explains the gradually increasing values of fracture resistance in MTA filapex groups over time. However, our results revealed that time lapsed after obturation doesn't significantly affect root fracture resistance.

\section{REFERENCES}

1. Levitan ME, Himel VT, Luckey JB. The effect of insertion rates on fill length and adaptation of a thermoplasticized gutta-percha technique. J Endod 2003;29:505-8.

2. Becker TA, Donnelly JC. Thermafil obturation: a literature review. General Dentistry 1997;45:46 -55.

3. Clinton K, Van Himel T. Comparison of a warm gutta-percha obturation technique and lateral condensation. J Endod 2001;27:692-5.

4. Trope M, Ray HL. Resistance to fracture of endodontically treated roots. Oral Surg Oral Med Oral Pathol Oral Radiol Endod 1992;73:99-102. 2.

5. Dang DA, Walton RE. Vertical root fracture and root distortion: effect of spreader design. J Endod 1989;15:294-301.

6. Uzunoglu-Özyürek E, Küçükkaya Eren S, Karahan S. Effect of root canal sealers on the fracture resistance of endodontically treated teeth: a systematic review of in vitro studies. Clin Oral Investig. 2018;22(7):2475-2485. doi:10.1007/s00784-018-2540-9

7. Kim YK, Grandini S, Ames JM, et al. Critical Review on Methacrylate Resin-based Root Canal Sealers. doi:10.1016/j.joen.2009.10.023

8. Ersoy I, Evcil MS. Evaluation of the effect of different root canal obturation techniques using two root canal sealers on the fracture resistance of endodontically treated roots. Microsc Res Tech. 2015;78(5):404-407. doi:10.1002/ jemt.22487

9. Sedgley CM, Messer HH. Are endodontically treated teeth more brittle? J Endod. 1992;18(7):332-335. doi:10.1016/ S0099-2399(06)80483-8

10. Phukan AH, Mathur S, Sandhu M, Sachdev V. The effect of different root canal sealers on the fracture resistance of endodontically treated teeth-in vitro study. Dent Res J (Isfahan). 14(6):382-388.

11. Peng L, Ye L, Tan H, Zhou X. Outcome of Root Canal Obturation by Warm Gutta-Percha versus Cold Lateral Condensation: A Meta-analysis. J Endod 2007;33:106-109.

12. Lertchirakarn V, Palamara JEA, Messer HH. Load and strain during lateral condensation and vertical root fracture. J Endod 1999;25:99-104.

13. Sagsen B, Er O, Kahraman Y, Akdogan G. Resistance to fracture of roots filled with three different techniques. Int Endod J. 2007;40(1):31-35. doi:10.1111/j.1365-2591.2006.01177.x 
14. Mandava J, Chang P, Roopesh B, Faruddin M, Anupreeta A, Uma C. Comparative evaluation of fracture resistance of root dentin to resin sealers and a MTA sealer: An in vitro study. J Conserv Dent. 2014;17(1):53. doi:10.4103/09720707.124140

15. Mittal A, Dadu S, Garg P, Yendrembam B, Abraham A, Singh $\mathrm{K}$. Comparative evaluation of fracture resistance of endodontically treated teeth with epoxy resin-based sealers ah plus and mineral trioxide aggregate fillapex: An in vitro study. Indian J Dent Sci. 2017;9(1):8. doi:10.4103/IJDS.IJDS_83_16

16. Chadha R, Taneja S, Kumar M, Sharma M. An in vitro comparative evaluation of fracture resistance of endodontically treated teeth obturated with different materials. Contemp Clin Dent. 2010;1(2):70. doi:10.4103/0976-237X.68590
17. Nagpal A, Annapoorna BM, Prashanth MB, et al. A Comparative Evaluation of the Vertical Root Fracture Resistance of Endodontically Treated Teeth The Journal of Contemporary Dental Practice. 13(3):351-355. doi:10.5005/ jp-journals-10024-1150

18. Patil P, Banga K, Pawar A, Pimple S, Ganeshan R. Influence of root canal obturation using gutta-percha with three different sealers on root reinforcement of endodontically treated teeth. An in vitro comparative study of mandibular incisors. J Conserv Dent. 2017;20(4):241. doi:10.4103/ JCD.JCD_233_16

19. Viegas OG. Analysis of the Interface between calcium silicate-based endodontic materials and root canal dentine: a pilot study. 2013 . 